\title{
NOTAS SOBRE LA OBRA CIENTÍFICA DE COSERIU (8)
}

\author{
JosÉ POLO \\ (Unniversidad Autónoma de Madrid)
}

II ARQUITECTURA DE LA LENGUA

2: paréntesis que desembocará en Coseriu (6)

\section{Francisco Abad Nebot}

0

Si no estoy equivocado, la línea principal de arranque de la atención a estas cuestiones por parte del profesor Abad viene de las enseñanzas, en letra de molde o por otros cauces, de Manuel Alvar (véase la entrega anterior). También aparecen en su obra, la del autor ahora objeto de estudio, referencias a Cuervo, a Diego Catalán, a José Pedro Rona y, naturalmente, como se verá enseguida, a don Vicente García de Dicgo, muy presente, como pudimos observar, en los trabajos y en las enseñanzas orales, de ocasión o sistemáticas, del maestro Alvar. Será el propio Abad Ncbot quien, en algún trabajo futuro relacionado con este campo, pueda aclararnos tal asunto: cl origen de sus inquietudes sociolingüísticas, al menos en la superficic, y, específicamente, cómo llegó a crearse en él la aureola de respeto y admiración por la figura de don Vicente García de Diego, sobre todo en lo relacionado con el decisivo 1926.

1. «Dialectos léxicos internos del castellano (caudal de vocabulario del Diccionario académico)», capítulo II, págs. 49-68, de la segunda parte de su libro El signo literario, Edaf, Ediciones-Distribuciones (Colección Edaf Universitaria, 8), Madrid, 1977. Lo de dialectos internos nos lleva automáticamente a García de 
Diego. Entre las páginas 54-56 se habla de este autor a propósito de su consideración de nuestra lengua como un complejo dialectal (con sus dialectos internos) e ideas subsiguientes (trabajos de 1950 y 1958 además, añado ahora yo, de la segunda edición, 1959, de su conocido manual dialectológico: véase la entrega anterior).

2. También en 1977 (la misma sede editorial de la ficha anterior y, dentro de la colección nombrada, con el número 14) publica nuestro autor la antología Lecturas de sociolingüística. Se recogen textos de I. Iordan, E. Coseriu, F. Marcos, M.Alvar, D. Catalán, H. López Morales, del propio Abad, G. Salvador, R. Menéndez Pidal y G. de Granda. Pero también se halla, colocado en el segundo lugar, de Vicente García de Diego, «Dialectos internos verticales», como sabemos, extraído de la acabada de aludir segunda edición de su Manual de dialectología española. En el mismo volumen se recoge, del responsable de la antología, «Diatopía y diastratía linguísticas», págs. 125-139. En la primera nota leemos: «De Ecología del lenguaje, en curso de publicación; preliminar de Amando de Miguel» (no me consta haya sido publicada tal obra conjunta, aunque sus materiales se hallan repartidos, fundamentalmente, entre dos obras de su autor de años posteriores). En estas notas del profesor Abad se observa la presencia sistemática de Manuel Alvar (citados varios trabajos).

3. «Dialectología y sociolingüística (introducción bibliográfica)», en su libro Los géneros literarios y otros estudios de filología, Cátedra de Lingüística General de la UNED [Universidad Nacional de Educación a Distancia], Madrid, 1982, páginas 35-41. Entre las páginas 35 y 36 aparecen fichados y comentados someramente tres trabajos de Manuel Alvar; y en la 38, dos de García de Diego: Problemas etimológicos (Ávila, 1926) y Manual de dialectología española (en la reedición o reimpresión de 1978: véase la entrega anterior). Reproduzco, separados mediante doble pleca negrita, los respectivos comentarios:

Defiende la ctimología vitalista, la que consigue la determinación cronológica, geográfica y social de una palabra, pues «no considera el lenguaje en la unidad artificiosa de la lengua oficial, sino como una vastísima complejidad de dialectos mutuamente influidos y como una superposición de dialectos sociales».llObra de consulta bien conocida, con agudo interés por todas las diferenciaciones interiores del idioma. Deben verse además los dos celebrados artículos de García de Diego, de RFE, III, 1919, pp. 301-318 [«Dialectalismos»], y XXXIV, 1950, pp. 107-124 [《El castellano como complejo dialectal y sus dialectos internos»]

4. «Estructura lingüístico-dialectal del dominio hispánico», cap. IV, págs. 42-49, de su libro Noticia de la lengua española, Cátedra de Lingüística General y Crítica 
Literaria de la UNED, Madrid, 1983. En la bibliografía de ese capítulo se mencionan los mismos dos trabajos comentados en la ficha anterior. Voy a reproducir el párralo 4.4 , págs. $47-48$, sin las notas 5 y 6 :

Junto a los dialectos diatópicos o geográficos existen, como es sabido, los cliastráticos o sociales [mejor: los del eje diatópico y los del eje diastrático], también llamados verticales [por el autor que enseguida será nombrado]. Entre nosotros, y al ingresar en la Academia en 1923 [1926], subrayaba ya García de Diego que «una lengua es intrincado polimorfismo», «vastísima complejidad de dialectos mutuamente influidos y... [los puntos suspensivos son del autor que cita el texto de 1926, no míos: JP] superposición de dialectos sociales» [aquí venía la nota 5 , con texto de Menéndez Pidal]. Luego García de Diego ha identificado como dialectos «vcrticales» «las modalidades estables de las hablas de las distintas clases sociales», así como las hablas técnicas y las jergas (el modo de expresarse -que será clímcro- de las actuales niñas chelis madrileñas, que califican de «guapas» unas botas que se han comprado, etc.).llSe debe al mismo prof. de [De] Diego el haber cnumerado distintos fenómenos del español vulgar en cuanto, precisamente, «dialecto vertical»; no obstante, la verdadera investigación sociolingǘstica es la que delimita la concreta vigencia o altura social de los fenómenos, la que contrasta el hablar diastráticamente. Entre esos rasgos que se han enumerado del español vulgar se hallan las pronunciaciones paine, sais; Usebio, Ulalia; tiatro, cuete; dispierto, imiente; melitar, medicina [medecina]; ná [na], sentá;... [puntos suspensivos sobrantes o mal colocados]. Formulaciones morfológicas vulgares son mesmo, nadie, ayer merendemos, tú tuvistes, andé, conducí, semos, etc. [aquí aparecía la nota 6, en la que sc remite a un trabajo, 1958, de J. P. Rona].

5. Diccionario de lingüística de la escuela española, Gredos, Madrid, 1986 (prólogo de Rafael Lapesa). Hay referencias a García de Diego, en los asuntos que nos afectan, en las entradas Complejo dialectal (la lengua española como), páginas 77-79, Dialectal (el lenguaje como complejidad), págs. 93-95, y Dialectos verticales, págs. 98-99. Cito de los dos últimos lugares, págs. 93 y 98 respectivamente:

Esta tesis [la del lenguaje en cuanto complejidad dialectal, la del español como complejo dialectal] fue enunciada tempranamente por García de Diego, quien [en el consabido 1926, que aparece fichado al final del texto] afirmaba: «La etimología vitalista no considera el lenguaje en la unidad artificiosa de la lengua oficial, sino como una vastísima complejidad de dialectos mutuamente influidos y como una superposición de dialectos sociales. Angustiosa complicación esta que la lengua nos ofrece; aunque siempre será mejor asombrarnos de la complejidad, [coma sobrante] que cngañarnos con una mentida sencillez. "La ciencia del lenguaje, dice Brunot, ha de descubrimos lo que el lenguaje es, sus cruces e inconsecuencias, su organización incstable, revesada y compleja, como es la naturaleza, no alineada y simplista, como la lalsa ciencia nos la presenta". Es pues un absurdo soñar con la uniformidad, si una 
Icngua es intrincado polimorfismo».ll«Son dialectos verticales — define García de Diego- las modalidades estables de las hablas de las distintas clases sociales. Los más importantes son el habla culta y el habla vulgar; pero hay otras peculiaridades importantes, como son las hablas técnicas de las profesiones y de los oficios, que suelen incluirse en buena parte en los diccionarios comunes, las jergas arraigadas tradicionalmente en algunos oficios, las jergas ocultistas de los pícaros y las jergas limitadas y cambiantes que surgen ocasionalmente en algunos medios».

6. «Dialectología vertical en el español contemporáneo», en Homenaje a Alonso Zamora Vicente, Castalia, Madrid, II (Dialectología. Estudios sobre el Romancero), 1989, págs. 13-24. Tras un punto de arranque en el que la ligura de García de Diego se impone de modo natural, hace entrar en juego ideas de José Pedro Rona, Diego Catalán y Manuel Alvar. Citaré la primera mitad del epígrafe Surgimiento de la dialectología social (págs. 13-14), luego el segundo párrafo de Hacia una visión integrada del idioma (pág. 17) y, finalmente, el párrafo inicial de Primeras conclusiones (pág. 19). Las notas que omitiré son meramente bibliográficas:

Es clásico mencionar como primera referencia entre nosotros a los dialectos sociales o verticales la que hace García de diego en su discurso académico de ingreso [omito nota 1], y resulta también no menos usual tomar sólo unas palabras suyas, [coma sobrante] que [,] aisladas de contexto [,] pueden ser menos completamente cntendidas; nosotros vamos a referirnos desde luego a las mismas [a ellas, a tales palabras], pero insertándolas en el razonamiento de conjunto de su autor.

Viene a postular García de Diego la que llama «etimología comparativa idealista» o «etimología de grupos ideológicos», que es la que ha de tener en cuenta las relaciones asociativas que en el depósito de la lengua vinculan a los vocablos entre sí: tal «como a la etimología fonética —expresa don Vicente- corresponde seguir en línea recta a las voces que han vivido una vida dormida, y a la idealista individual proseguir la ruta psicológica que cada palabra independiente ha seguido, toca a esta etimología comparativa el seguir los grupos de palabras cuando se sospecha que por ser íntimos los contactos de su vida común ideal han de habcr quedado en la forma inclelebles huellas de éstos [omito nota 2]》». Se trata por tanto de buscar en las formas materiales los resultados de la asociación de ideas y vocablos.

Párrafos más adelante, García de Diego concluirá postulando: «Siendo pues la cvolución lingüistica un hecho más sujeto aún que a la fonética a la acción mental, no hay más remedio que sustituir en la etimología la fórmula clásica tal palabra de tal otra por expresiones complejas en que se retrate el complicado influjo ideal» [omito nota 3]; así el etimologista descubrirá el giro que la fantasía popular ha podido imprimir a las palabras. En el contexto de este discernimiento acerca de lo que es expresión o es contenido en el todo del lenguaje, alude nuestro autor a otras complejidades más del idioma, y entonces es cuando advierte cómo resulta «un absurdo soñar con la uniformidad, si una lengua es intrincado polimorfismo $\mathrm{c}$ 
indeterminable irradiación ideal», «una vastísima complejidad de dialectos sociales mutuamente influidos y... [puntos suspensivos de quien está citando a García de Dicgo, no míos: JP] una superposición de dialectos sociales» [omito nota 4]. El idioma - pues- consiste en una forma de la expresión más una forma del contenido vinculadas y actuantes entre sí, y se halla distribuido según (entre otras cosas) niveles sociales $[0]$ verticales por igual vinculados y actuantes entre ellos.

No obstante estas anticipaciones de García de Diego y cualquiera [cualesquiera] otras que se quieran buscar incluso en él mismo [véase la entrega número 6 de esta seric], la verdad es que la ciencia linguística no vendría a hacerse cargo de un modo sistemático de la dialectalidad interna vertical del idioma hasta la década de los años sesenta [afirmación discutible: ya Coseriu, en 1958, en congreso, había cimentado la perspectiva de lo sociocultural en el lenguaje: véase la entrega número $2, \$ 5-\mathrm{A}]$. Entrc los autores de habla hispana se adelantó ligeramente José Pedro Rona, en un a modo de manifiesto programático que también es necesario conocer: el que llamó Algumos [palabra que no pertenece al título de la obra] aspectos metodológicos de la dialectología hispanoamericana [omito nota 5; en su momento estudiaré, dentro de csla scric, las relaciones entre maestro, Coseriu, y discípulo, Rona, en torno al asunto que nos ocupal.

Ya al preparar unas adiciones a la edición castellana de la Lingüística románica de Iordan, dedica [Alvar] un párrafo a los Problemas etimológicos de García de Diego, cogiendo por una parte su postura etimologista y por otra la idea de la complejidad social vertical del idioma [véase la entrega anterior]; Alvar sintetiza (por ejemplo) que para García de Diego «la nueva etimología necesita no sólo de las leyes lonéticas (positivismo), sino también de cultura folklórica (palabras y cosas), de distribución geográfica y de métodos psicológicos (idealismo)» [omito nota 14]. Pero sobre todo este investigador manifestó su visión en páginas recogidas luego en los volúmenes Estudios canarios [omito nota 15] y Estructuralismo, geografía lingiïstica y dialectología actual [omito nota 16].

El análisis de textos representativos que venimos haciendo nos permite darnos cucnta de que naturalmente un hecho tan nítido como el de la estratificación social de la lengua no podía haber pasado desapercibido [inadvertido]; García de Diego, en concreto, notó tal superposición de dialectos o haces e isoglosas sociales y a la vez. su interrelación, hechos éstos que se dan en toda comunidad idiomática.

7. «Lingüística variacional del español», contribución número 404, SPANISCH: VARIETÄTENLINGUISTIK DES SPANISCHEN, págs. 607-616 en el volumen VI-1, 1992, de Lexikon der romanistischen Linguistik (LRL), Max Niemeyer Verlag, Tubinga (responsables cditoriales: Günter Holtus, Michael Metzeltin y Christian Schmitt). El cpígrale segundo se titula La lengua como complejidad de dialectos (págs. 607- 
609); el tercero, Coexistencia de sistemas (págs. 609-610). En ambos se halla presente Vicente García de Diego, citado o parafraseado en relación con sus trabajos, ya mencionados, de 1926, 1950 y 1959 (o sea, en la segunda edición del manual dialectológico de 1946); vale decir: dialectos sociales y dialectos internos verticales más alguna otra idea complementaria. Esta vez no voy a reproducir texto alguno, pues resultaría prolijo, por la propia estructura, forzosamente condensada, del trabajo del profesor Abad (seguramente me vería obligado a extenderme en alguna que otra aclaración) y porque se trata de textos que ya han aparecido citados y de los que, justamente por ello, se puede prescindir en un caso como este.

8. «La idea de los dialectos verticales», epígrafe, págs. 106-111, del capítulo IV, «Dialecto», págs. 91-115, de su libro Nueve conceptos fundamentales para los estudios filológicos, UNED, Madrid, 1992. Texto, el del epígrafe, muy relacionado, como ya cabe esperar cotejando los respectivos títulos, con el de la ficha número 6 . No obstante, a pesar de su similitud, voy a reproducir los segmentos, continuos, que atañen a García de Diego (omitiré las notas: $37-41$ ):

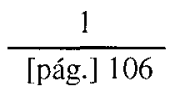

Aunque dedicado a discurrir acerca de «Problemas etimológicos», el discurso académico de ingreso de don Vicente García de Diego iba a formular la idea de la dialectalidad interior de la lengua en cuanto el sistema idiomático se halla escindido efectivamente según también dialectos sociales [1926] o «verticales» [1959].

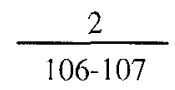

García de Diego proclama que la lengua va siempre indefinidamente matizándose, cs decir, que varía y cambia: pueden cambiar los vocablos en concreto de acuerdo con los grupos ideológicos a los que pertenezcan, y así toca al método comparativo idcalista «el seguir los grupos de palabras cuando se sospecha que por ser íntimos los contactos de su vida común ideal han de haber quedado en la forma indelebles hucllas de éstos» [omito nota 37]. Cualquiera de los idiomas romances no es herencia muerta [Ninguno de los idiomas romances es herencia muerta], y por tanto al analizar uno de ellos no se puede prescindir «de la posterior colaboración de las multitudes, a las que se deben la mayor parte de las derivaciones y de las desviaciones semánticas» [omito nota 38].

$$
\frac{3}{107}
$$

En definitiva [,] García de Diego quiere venir a parar a que el idioma es polimorfismo e irradiación etimológica ideal, y para ello se adhiere a la tesis más 
general (que expresa quizá por vez primera de manera enteramente nítida entre nosotros) de la lengua en tanto superposición y complejo de dialectos, tanto gcográficos como sociales. Citando además a Jaberg y a Brunot, nuestro autor dirá [reproduzco a continuación, separado por doble pleca negrita, el texto de García de Diego citado, sangrado y en cuerpo menor, por el profesor Abad]:llLa etimología vilalista no considera el lenguaje en la unidad artificiosa de la lengua oficial, sino como una vastísima complejidad de dialectos mutuamente influidos y como una superposición de dialectos sociales. «Si no buscamos, dice Jaberg, una falsa simplificación, la evolución de las palabras se ofrece en una complicación desconcertante para el que las miraba desde el punto de vista de la lingüística clásica; más ésa es la realidad, y ante ella los métodos simplicistas de la investigación ctimológica tienen que fracasar». Angustiosa complicación ésta que la lengua nos ofrece; aunque siempre será mejor asombrarnos de la complejidad que engañarnos con una mentida sencillez. «La ciencia del lenguaje, dice Brunot, ha de descubrirnos lo que el lenguaje es, sus cruces e inconsecuencias, su organización inestable, revesada y compleja, como es la naturaleza, no alineada y simplista, como la falsa ciencia nos la presenta». Es pues un absurdo soñar con la uniformidad, si una lengua es intrincado polimorfismo e indeterminable irradiación ideal [omito nota 39].

\section{$\frac{4}{107}$}

Años más adclante, al cscribir su Manual de dialectología, García de Diego dedica un capitulillo a los rasgos del castellano vulgar, y engloba a esta lengua vulgar [.] que considera «londo común del pueblo rústico, y también en parte del bajo pueblo ciudadano y aun del habla descuidada de la gente culta» [en el original, «del pueblo rústico y lambién, en parte, del bajo pueblo ciudadano, y aun»], en el todo de los «dialectos internos verticales» que integran a un idioma [omito nota 40].

$$
\frac{5}{107-108}
$$

Dialcctos verticales - va a definir - son los conjuntos de rasgos que caracterizan el hablar de los grupos sociológicos: «Son dialectos verticales (escribc) las modalidades estables de las hablas de las distintas clases sociales. Los más importantes son el habla culta y el habla vulgar; pero hay otras peculiaridades importantes, como son las hablas técnicas de las profesiones y de los oficios, que suclen incluirse en buena parte en los diccionarios comunes, las jergas arraigadas tradicionalmente en algunos oficios, las jergas ocultistas de los pícaros y las jergas limitadas y cambiantes que surgen ocasionalmente en algunos medios».

$$
\frac{6}{108}
$$

Vemos pues que en sentido amplio García de Diego tiene por dialectos verticales a aquellos conjuntos de rasgos idiomáticos -0 de isoglosas, podríamos decir- 
presentes característicamente en los estratos socioculturales de hablantes según su propia adscripción social, o según oficios, agrupaciones, etc.

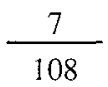

La otra alusión clásica a la diferenciación vertical del idioma antes de que lá idea se hiciese ya «idea recibida» en la comunidad profesional es la de José Pedro Rona. En un escrito absolutamente vigente hoy dia y que - se le cito o no- caló de hecho en los profesionales hispanos, Rona hablaba de modo explícito [siguiendo en ello a su maestro Eugenio Coseriu: véase atrás 6-1] de los «niveles dialectales» existentes en el seno de una comunidad idiomática, estableciendo que se trata de rasgos lingüísticos adscribibles a los distintos estratos socioculturales de la comunidad concreta global: «Vemos pues - escribía - que a cada fenómeno comprobado en el habla de determinada capa socio-cultural de cierto lugar pueden asignársele dos valores diferentes. En comparación con los lenómenos de otras capas socioculturales del mismo lugar, la diferencia es de nivel. En comparación con el habla de niveles iguales de otros lugares [,] la diferencia es dialectal [fiel trasunto de las ideas de Coseriu, de quien las recibió oralmente y por escrito, incluso en textos de circulación interna que rodaron un tiempo antes de su publicación]» [omito nota 41 , donde el volumen de Rona Aspectos metodológicos de la dialectología hispanoamericana, 1958, es citado, por segunda vez con error - véase atrás 6-1-, como Algunos aspectos.....

9. «La variación lingüística» (compárese atrás ficha 7), en Revista Española de Lingïística, 23-1/1993, págs. 73-86. En la entrega número 4 de esta serie, \$3, me ocupé de este trabajo en cuanto en él se mencionaba a Rufino José Cuervo, Hugo Schuchardt, Américo Castro y otros en el asunto de lo «sociolingüístico». Ahora lo traigo aquí por su referencia al estudioso que viene ocupando nuestra atención. En clecto: en cl epígrafe tercero, Saussure: los «caracteres dialectales», págs. 79-82, nos interesan unas líneas de las páginas 80-81, a saber:

Tampoco escapó a Saussure la complejidad diacrónica que adquierc un código dialcctal cuando se ha hecho la lengua común y oficial: al dialecto privilegiado - decía- - «se le mezclan elementos dialectales de otras regiones; se hace cada vez más complejo» [omito la nota 26 , con la remisión a la página 312 del Curso en la traducción de Amado Alonso en Losada]; se trata en efecto de que 1.] al ir hacićndose diacrónicamente [mejor: históricamente] [,] toda lengua acaba por consistir en un «complejo dialectal» como resultado de la mezcla de las hablas.

Para el caso castellano, sabido es que fue Vicente García de Diego quien, acaso asegurando sus ideas en Saussure, propuso e ilustró la fórmula de que nuestra lengua consiste en un «complejo dialectal» de «dialectos internos»; la lengua española resulta así rica en dialectalismos [...]. 
10. «Problemas de periodización y caracterización en historia de la lengua literaria cspañola», en Revista de Filología Románica, XV/1998, págs. 13-33. Cito de la página 15:

El análisis lingüístico deberá atender —enseñan los filólogos praguenses_ a la diastratía idiomática I,I que se manifiesta, por ejemplo, en las hablas urbanas (entre nosotros lo pidió más o menos análogamente y antes de ellos García de Diego, y lucgo lo han pedido en una u otra fórmula José Pedro Rona, Diego Catalán, Juan Miguel [Manuel] Lope Blancha [Blanch], Manuel Alvar [...].

Tal como anunciaba al comienzo de la presente entrega, por los textos del prolesor Abad Nebot que he citado (todos aquellos conocidos por mí en los que se menciona al García de Diego de 1926 y, complementariamente, de 1950 y 1959), habrá podido observarse que la inspiración directa de su ruta hacia nuestro dialectólogo há venido fundamentalmente a través de Manuel Alvar, idea que Lodavía quedaría más clara repasando otros estudios de $\mathrm{F}$. Abad en los que la presencia del maestro Alvar es sistemática y persistente (y que no he citado yo aquí por no encontrarse en ellos referencias a esos hitos clásicos de García de Diego). Pero, al mismo ticmpo, se han visto referencias de naturaleza varia a Diego Catalán (a Menéndez Pidal en texto de nota que no he citado) y, sobre todo, a José Pedro Rona, lo mismo que, en el último trabajo manejado por mí (atrás ficha 9), a Schuchardt, A. Castro y, de especial interés, el posible enlace Saussure/García de Dicgo, concxión que no pierde interés por el hecho de que, como yo sospecho, no se haya dado de forma directa; vale decir: que, si don Vicente García de Diego se inspiró en alguien para su formulación de 1926 (además de en los mencionados por él: Jaberg, Brunot, Dauzat...), probablemente fue en autores distintos del maestro ginebrino, aunque tal vez csos cstudiosos, fuente presumible del filólogo español, hubicran, por su parte, bebido, directa o con carácter muy próximo a ello, en las fuentes del considerado crcador de la lingüística moderna. Valdría la pena indagar al respecto.

(continuará) 